\title{
Mission Optimisation for a Conceptual Coaxial Rotorcraft for Taxi Applications
}

\author{
J. Enconniere ${ }^{\mathrm{a}, *}$, J. Ortiz-Carretero ${ }^{\mathrm{a}}$, V. Pachidis ${ }^{\mathrm{a}}$ \\ ${ }^{a}$ Cranfield University, College Rd, Cranfield, Bedfordshire MK43 OAL, UK
}

\begin{abstract}
This paper presents the development and an application of a multidisciplinary methodology for the preliminary design assessment of compound coaxial rotorcraft with a counter-rotating rotor system and a rear-mounted propeller. A comprehensive optimisation strategy is deployed to evaluate the environmental and operational benefits of the aforementioned rotorcraft architecture. The code is validated against experimental data prior to the application of the methodology to the evaluation of a conceptual vehicle for intercity taxi applications. Response Surface Models (RSMs) are generated to mimic the rotorcraft performance in order to accelerate the optimisation process. The effects of the defined mission input parameters such as cruise speed, altitude, climb rate or mission length are evaluated. Pareto fronts for fuel burn, $N O_{x}$ emissions and mission duration are obtained. The method was applied to a hypothetical scenario of mission length ranging from 50 to $300 \mathrm{~km}$. Best estimate mission scenario are selected from the Pareto fronts, providing on average $23 \%, 20 \%$, and $13 \%$ simultaneous reductions in mission duration, fuel burn, and $N O_{x}$ emissions when compared to a conventional flight procedure. The picked scenarios coincide with the fuel optimised mission scenarios for each mission length, thus the multi-disciplinary environment was not required. Besides, an "improved" mission procedure is outlined, defining the mission characteristics independently of the mission's length. This procedure yields on average $22 \%, 14 \%$, and $8 \%$ reductions in mission duration, fuel burn, and $N O_{x}$ emissions, respectively.
\end{abstract}

Keywords: compound rotorcraft, coaxial rotor, performance simulation, mission analysis, gaseous emissions, optimisation

\section{Introduction}

\subsection{General Context}

The integration of innovative technologies in modern aircraft is strewn with obstacles. Not only any new system must fit with the safety and regulation standards, but also it must be proven to be serviceable and efficient in the highly competitive aerospace industry. Indeed, the cost of introducing any innovation is extremely high and time-demanding. Therefore, robust and cost effective multidisciplinary design and assessment tools are of prior importance for manufacturers in order to decide on the integration of any considered system or architecture on a preliminary design stage.

The attention of design engineers when it comes to deciding upon a technology is drawn toward: (i) the continuous rise in global energy demand, resulting inevitably in an increase in fuel price and the potential depletion of fossil fuel reserves, (ii) the growing concern for environmental impact, including chemical and noise emissions, and (iii) the sharp growth of rotorcraft operations expected in the future. Coming back to (i) and (ii), aerospace activities are currently a relatively small contributor to the global carbon dioxide $\left(\mathrm{CO}_{2}\right)$ footprint, with an estimated $2 \%$ share of the worldwide emissions [1. However, the aircraft industry

\footnotetext{
* Corresponding author

Email address: j.p.enconniere@cranfield.ac.uk (J. Enconniere)
} 
is the fastest growing carbon emitter [2, it is also responsible for the emission of hazardous gases such as nitrogen-oxides $\left(N O_{x}\right)$ [3].

As mentioned above, point (iii) reflects the concern for the expected aviation traffic rise. In fact, air traffic has more than doubled in Europe in the last two decades [4. Furthermore, EUROCONTROL forecasts the European traffic in 2050 to be twice the year 2012 one 5 . Nowadays, homeland defence, search and rescue, law enforcement, oil rig services represent the main domain of rotorcraft activity. Rotorcraft operations represent an annual average of about 1,500,000 flight hours, a small figure compared with the 10,000,000 hours flown by European commercial airlines [6]. However, by virtue of their versatility, rotorcraft can operate in the direct vicinity of densely populated areas. These operations, particularly passenger transport/air taxi, which has been a marginal activity until now, are expected to boom in the near future [6].

The Advisory Council for Aeronautics Research in Europe (ACARE) set ambitious environmental goals for "vision 2020" under the Strategic Research and Innovation Agenda [7. It targets a sustainable aviation growth, including a $50 \%$ reduction in $\mathrm{CO}_{2}$ emission through reduction of fuel consumption, and $80 \%$ reduction in $N O_{x}$ emissions, relative to the year 2000. These targets were extended on the "Flightpath 2050" agenda, with a $75 \%$ reduction of $\mathrm{CO}_{2}$ and $90 \%$ of $\mathrm{NO}_{x}$ emissions by 2050 relative to the year 2000 [8].

\subsection{Multidisciplinary Design Analysis and Optimisation Framework}

According to Clarke 9], abatement of the environmental impact of aircraft operations is achievable by either (i) reducing the number of operations, (ii) modifying the type of aircraft or (iii) changing the aircraft flight procedures. With the aforementioned expected growth of rotorcraft activities, point (i) is not a viable solution. The time-scale required to develop a new aircraft concept from conception to certification is counted in decades 10, therefore point (ii) can only be considered for rotorcraft concepts well advanced in the development phase. With this in mind, the authors' interest turned toward the recently unveiled Sikorsky S-97 11]. The S-97 follows the Sikorsky X2 Technology Demonstrator (X2TD) program, initially targeted for military activities, it would come as no surprise if civil derivatives are proposed in the next decade. The vehicle innovation comes with the use of a coaxial counter-rotating lift-offset rotor with a pusher propeller. The compound architecture has reached unprecedented speed and range during the X2TD flight program [12. As mentioned by Johnson et al. [13], such architectures result in a compact and manoeuvrable design suitable for urban applications. However, they limited their work to the design and performance aspects of conceptual coaxial rotorcraft for military applications, thus the environmental impact of the technology was not considered.

In order to effectively assess the benefits of the aforementioned configuration for civil applications, the use of multidisciplinary computational tools during the rotorcraft conceptual design stage is paramount to provide suitable design candidates. Several rotorcraft flight dynamics simulation codes have shown in the past the ability to assess innovative technology in terms of performance and environmental impact [6, 14, 15].

The abilities of the discussed rotorcraft place the compound architecture in a different class. It combines elements of fixed and rotating wing architectures, resulting in a versatile platform with many potential applications. Therefore, the benefits associated with these concepts need to be carefully assessed at mission level, before any benefits at global fleet level can be quantified.

D'Ippolito et al. [6] describe the deployment of a multidisciplinary simulation framework for rotorcraft environmental impact assessments. It highlights the need for several tools to successfully estimate gaseous and noise emissions of rotorcraft operations. A flight mechanics tool calculating helicopter trim and dynamic performance for manoeuvres sets the base of the tool. A rotorcraft environmental noise analysis program and an engine performance and gas emission code complete the framework. An optimisation strategy was deployed to effectively evaluate an optimum take-off manoeuvre with regards to fuel burn, and gaseous and noise emissions. Two steps were followed: the design exploration and approximation, and the optimisation approach. The first step demonstrated the need for a design of experiments synthesised into metamodels which approximates the complex relations between the inputs and outputs of the optimisation study with linear correlation coefficients. Response Surface Model (RSM) were subsequently created based on least squares fitting Taylor polynomials. Although the use of RSM is specific to one problem and simplifies the complex interrelations between the parameters, it is extremely powerful for fast optimisation. 
Goulos et al. 14] applied a similar methodology to the global optimisation of multidisciplinary design rotorcraft operations in terms of mission fuel burn, gaseous emissions and ground noise impact. The method was applied to two generic missions representative of typical rotorcraft operations. Trajectories were optimised to obtain reductions in fuel burn, gaseous emissions and ground noise impact. The method was also employed for optimisation of conceptual rotorcraft powerplant [16, highlighting the use of RSM moves part of the computational effort from the optimisation process to the generation of the RSM. Besides, they are specifically generated for one optimisation study, therefore freezing all the non-optimised parameters such as the mission design itself, restricting the usage of the RSM.

In light of the background, a comprehensive evaluation of conceptual rotorcraft systems and architectures necessitates the deployment of a multidisciplinary rotorcraft simulation framework in a global optimisation environment.

\subsection{Scope of the Present Work}

Although the interest in compound rotorcraft architectures has risen in the last decade, the benefits of such vehicles remain unclear. A complete assessment of this rotorcraft design in terms of fuel burn and gaseous emissions has not been addressed in a coherent multidisciplinary manner. This paper proposes a methodology to evaluate the performance of conceptual coaxial rotorcraft with pusher propeller architectures specifically. An integrated rotorcraft multidisciplinary design and optimisation framework was deployed for preliminary analysis of conceptual rotorcraft with the aforementioned architecture. It subsequently executes mission performance assessment in an optimised environment. Hence, the synergy between vehicle performance and mission procedure is captured.

A conceptual 3-tonnes rotorcraft representative of the aforementioned technology is studied for intercity taxi application. The design space includes the mission profile parameters, i.e. climb rate and speed, cruise speed and altitude, and descent rate and speed chosen to optimise mission fuel burn, $\mathrm{CO}_{2}$, and $\mathrm{NO}_{x}$ emissions as well as mission duration. As $\mathrm{CO}_{2}$ emissions are proportional to fuel burn, only the mission fuel burn is kept in the optimisation study. Prior to any optimisation, Response Surfaces Models (RSMs) are generated to reduce the computational effort of the proposed method. The metamodels of the rotor and propeller provide the power required of the two systems within the rotorcraft flight envelope.

The optimisation routine developed is coupled with Distributed Evolutionary Algorithms in Python (DEAP) 17, providing a multi-objective optimisation environment. Among the different methods available, a Genetic Algorithm (GA) was employed to generate the Pareto fronts for mission duration, mission fuel burn and $N O_{x}$ emissions. The methodology provides all the tools required to assess any conceptual compound rotorcraft in terms of environmental and operational performance.

\section{Numerical Formulation}

\subsection{Optimisation Framework}

The schemed work requires an effective multidisciplinary rotorcraft performance simulation framework integrated within a multi-objective optimisation environment. The complete package allows for conceptual rotorcraft assessment, capturing the synergy between rotorcraft performance and mission procedure. The modelling approach comprises several numerical modules, i.e. a rotorcraft performance model solving the non-linear system of equations for trim, an engine off-design performance simulation module, a gaseous emissions prediction tool, and a flight path analysis model based on the World Geodetic System date 1984 (WGS84). A mission analysis module is also integrated estimating the unknown mission fuel burn through an iterative process. Several additional modules are required to provide an effective optimisation strategy. RSMs are extensively used to replace the Coaxial Rotorcraft Performance Model (CRPM) in the mission analysis and the optimisation strategy to avoid the repetitive vehicle trim calculations. The multi-disciplinary optimisation framework is shown in Figure 1 . 


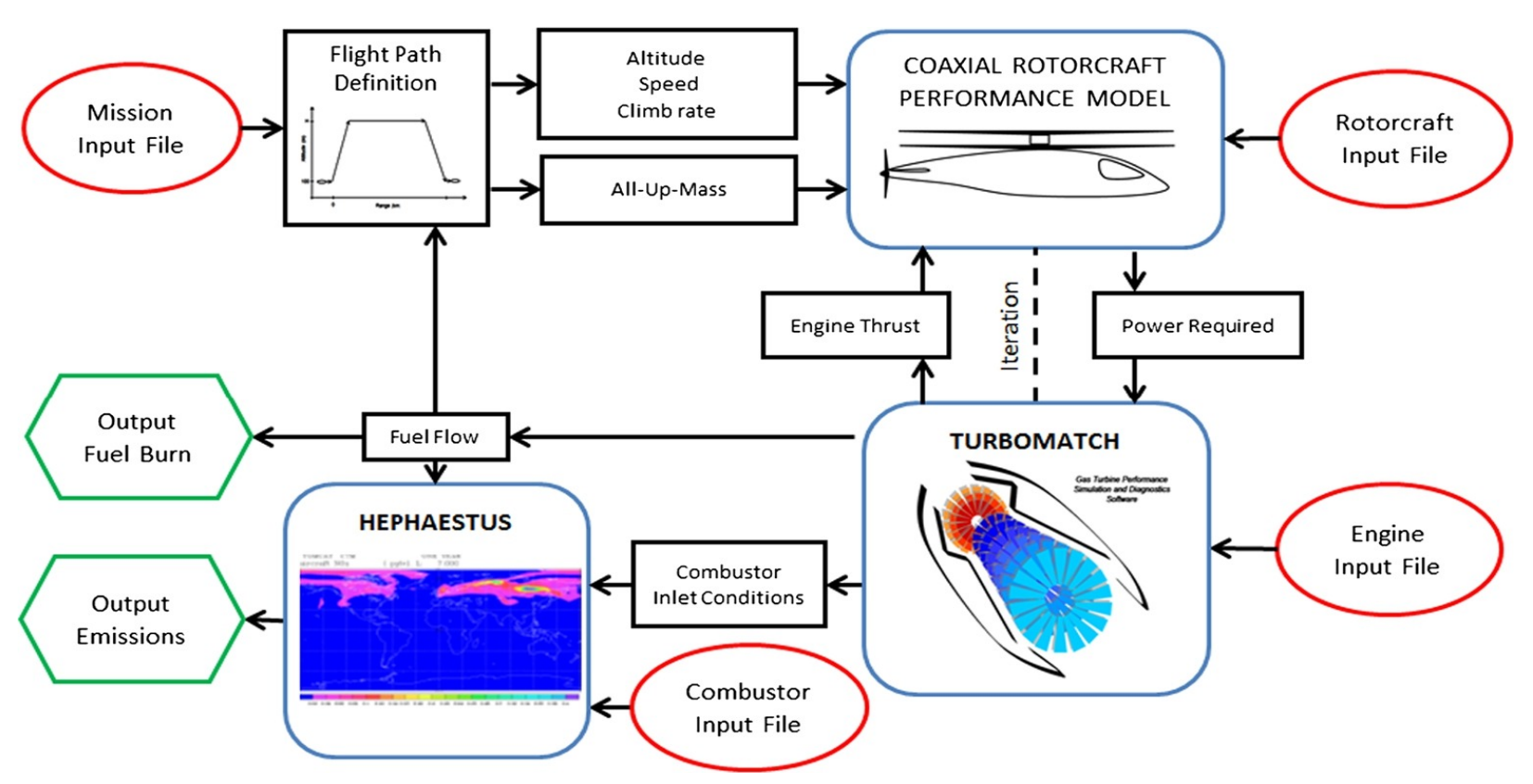

Figure 1: Multi-disciplinary rotorcraft performance optimisation framework

\subsection{Rotorcraft Performance Model}

The cornerstone of the framework as shown in Figure 1 is CRPM. The methodology followed is based on the level 1 of the rotorcraft model hierarchy proposed by Padfield [18. It solves the non-linear system of equations for trim by evaluating the rotors' inputs. The wake-induced velocity at the rotors is expressed as a superposition of finite flow states within a first order dynamic inflow estimation. The first harmonic Pitt \& Peters inflow model [19] was used, corrected to take into account the coaxial rotors' interactions as well as the propeller through the adaptation of the method proposed by Yana et al. [20] to forward flight.

In order to certify the coaxial rotor model, it was compared against the rotor 1 of Harrington's coaxial experiments 21] and a high fidelity coaxial simulation code based on a Vorticity Transport Model (VTM) 22]. The employed method evaluates relatively well the performance of the rotor at hover as illustrated in Figure 2(a), For the forward flight conditions, the model was only evaluated against the VTM model. The power demand is over-predicted at low speed up to advance ratio 0.05 , then between 0.05 and 0.15 , the model slightly diverges from the VTM to converge back at high advance ratios where good agreements are found between both models (Figure 2(b)].

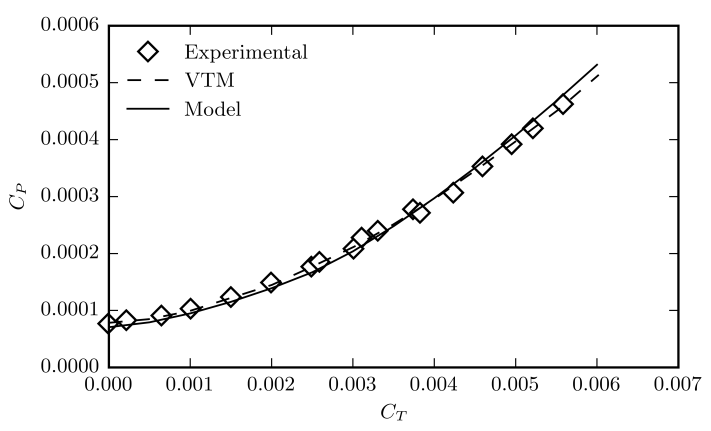

(a)

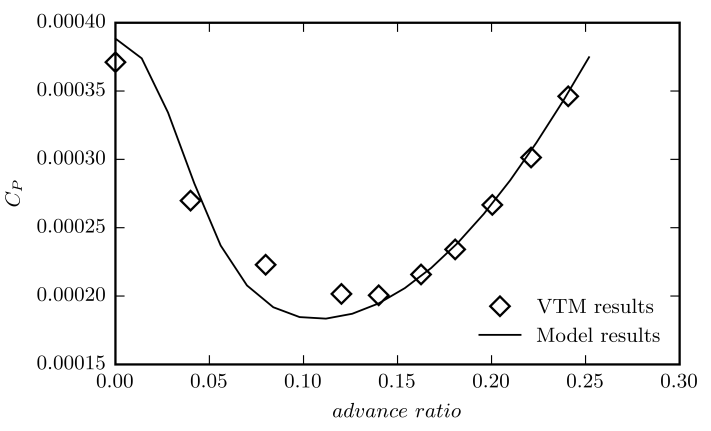

(b)

Figure 2: (a) Comparison between the coaxial rotor model and the Harrington's rotor 1 at (a) hover and at (b) forward flight 21,22

The coaxial rotor model is a key part of CRPM. The fuselage, wings, and propeller are also accounted for in the trim calculations. As seen in Figure 6, a gas turbine engine off-design performance analysis module is also integrated providing the engine fuel flow and the residual thrust. The integrated engine performance simulation model is a long-standing tool developed at Cranfield University and called TURBOMATCH [23]. 
It is a validated code capable of simulating the performance of any aero and industrial gas turbine engine at steady/transient state, design/off-design point and any level of degradation. Thus, it caters for the engine operating point at any flight condition [18, 24. Moreover, TURBOMATCH has already been proven reliable for rotorcraft performance assessments in the past [15.

Once the engine performance code is integrated, the framework goes through a second level of verification with the Sikorsky X2TD rotorcraft. The main flight test data are available in [12] and main characteristics of the vehicle are accessible in [25. One of the key benefits of a coaxial rotor system is its capability of lift offset. In other words, the retreated side of the rotor can be off-loaded thanks to the presence of the second counter-rotating rotor, cancelling the stall issue at high speed of the retreating blades. The lateral trim is achieved by balancing the rolling moments transmitted to the hub by the opposing advancing blades of the coaxial rotor system. The rolling moment $M_{\text {roll }}$ must be restricted to limit the mechanical constraint resulting on the rotor shaft and the tip clearance of the two rotors. Therefore, $M_{\text {roll }}$ was characterised thanks to the following equation:

$$
M_{\text {roll }}=K_{\text {roll }} L_{o f f s e t}^{100} V R_{\text {rotor }} A U M
$$

$L_{o f f s e t}^{100}$ is the lift offset at $\mathrm{V}=100 \mathrm{~m} / \mathrm{s}$ in percentage. The equation and $L_{\text {offset }}^{100}$ are chosen in order to correlate the model with the flight test data of the X2TD. The equation also sets $M_{\text {roll }}$ to zero at hover as lift offset does not bring any benefits in that condition. Figure 3 displays the comparison between the X2TD and the model for several $L_{o f f s e t}^{100}$ values $(10 \%, 15 \%$, and $20 \%)$. The rotor behaviour is relatively well catered for $L_{o f f s e t}^{100}=15 \%$. This law is kept for the subsequent studies.

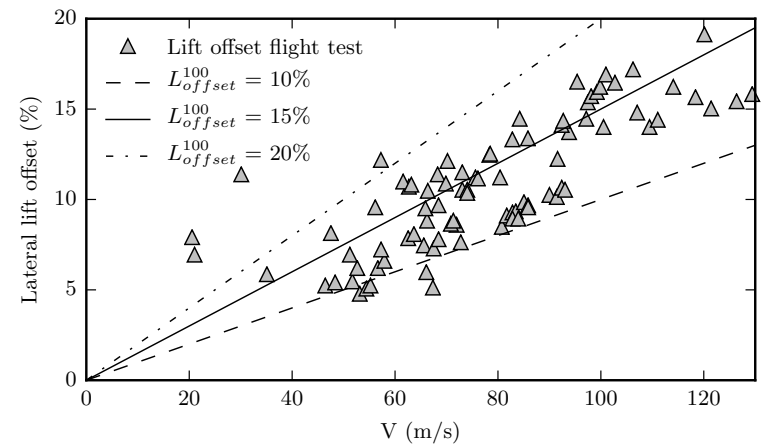

Figure 3: Lift offset, X2TD flight test data versus model for different $L_{\text {off } f \text { set }}^{100}$

Not only the rear mounted propeller makes it possible to reach high cruise speed, but it also results in a thrust compounding. Thrust compounding allows the vehicle to fly at different airframe pitch attitude $\left(\alpha_{0}\right)$ for a given flight condition. In other words, the lift and the propulsive force are a compound of the rotor and the propeller thrusts. $\alpha_{0}$ decides on the shared effort of the rotating systems. Above $60 \mathrm{~m} / \mathrm{s}$, the X2TD was flown at a $\alpha_{0}$ of $2-5^{\circ} 12$. The rotorcraft total power, $P_{\text {total }}$, is plotted for $\alpha_{0}=0$ and $5^{\circ}$ in Figure 4 with the rotor power $\left(P_{\text {rotor }}\right)$ and propeller $\left(P_{\text {prop }}\right)$. $P_{\text {total }}$ is genuinely lower with $\alpha_{0}=0^{\circ}$ than with $\alpha_{0}=$ $5^{\circ}$, principally at high speeds. The power distribution between the rotating systems is also greatly impacted at high speeds. As $\alpha_{0}$ increases, the rotor enters a wind-milling state, as seen in Figure 4(b) resulting in a thrust component opposite to the forward direction which must be compensated by the propeller, resulting in an increase of $P_{\text {prop }}($ Figure $4(\mathrm{c})$. .

At high speed, the X2TD was flown with an autorotating rotor system. $\alpha_{0}$ is chosen accordingly in the model. It must be evaluated depending on cruise altitude $H, \mathrm{AUM}, V$, and $V_{C}$. Therefore, $\alpha_{0}$ was defined by the following equation:

$$
\alpha_{0}=\alpha_{01}(V, A U M, H)+\alpha_{02}\left(V, V_{C}\right)
$$




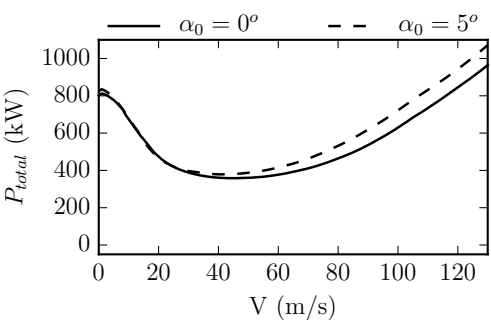

(a)

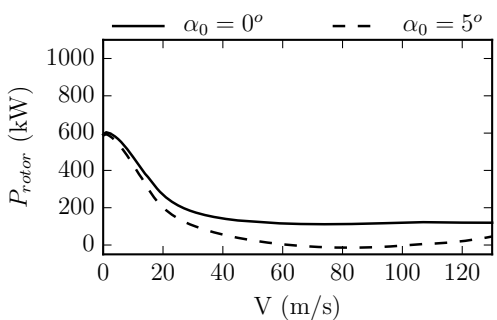

(b)

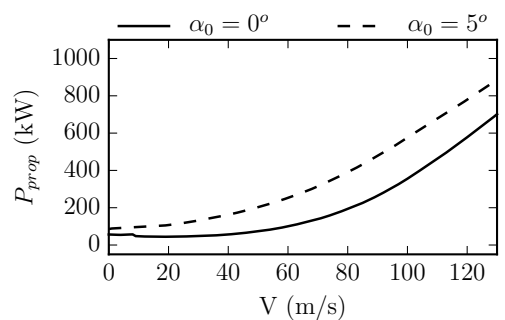

(c)

Figure 4: Rotorcraft (a) $P_{\text {total }}$, (b) $P_{\text {rotor }}$, and (c) $P_{\text {prop }}$ for $\alpha_{0}$ equals $0^{\circ}$ and $5^{\circ}$ degrees

The effect of altitude and AUM are catered by $\alpha_{01}$ while $\alpha_{02}$ determines the behaviour of the vehicle in climbs and descents. $\alpha_{01}$ is defined as a metamodel built with the results of the performance evaluation of the model at different flight conditions. $\alpha_{02}$ is characterised by an equation of the form:

$$
\alpha_{02}\left(V, V_{C}\right)=k V^{n} \tan ^{-1} \frac{V_{C}}{V}
$$

Once $\alpha_{0}$ is known, the performance of the rotorcraft is calculated applying a simplified version of the Euler's equation for the kinematics of a rigid body. The system of equations is solved following a NewtonRaphson iterative process. Each iteration needs a re-estimation of the aerodynamic forces and power required of each rotor. It eventually estimates the control inputs (collective, longitudinal cyclic, lateral cyclic for both counter-rotating rotors and collective for the propeller) in order to minimise the 3-dimensional forces and moments to reach a state of equilibrium.

The performance comparison between the X2TD and the model is shown in Figure 5. The model evaluates relatively well the power required from the rotating systems at speeds above $60 \mathrm{~m} / \mathrm{s}$. However, $P_{\text {rotor }}$ is under-evaluated at low speed, between 20 and $60 \mathrm{~m} / \mathrm{s}$. At the given AUM $=$ MTOW and $H=$ $1500 \mathrm{~m}, \alpha_{0}$ gradually increases from $1^{\circ}$ to reach a plateau above $100 \mathrm{~m} / \mathrm{s}$ at approximately $5^{o}$. All in all, the performance of the X2TD is relatively well catered, providing confidence in the rotorcraft performance model.

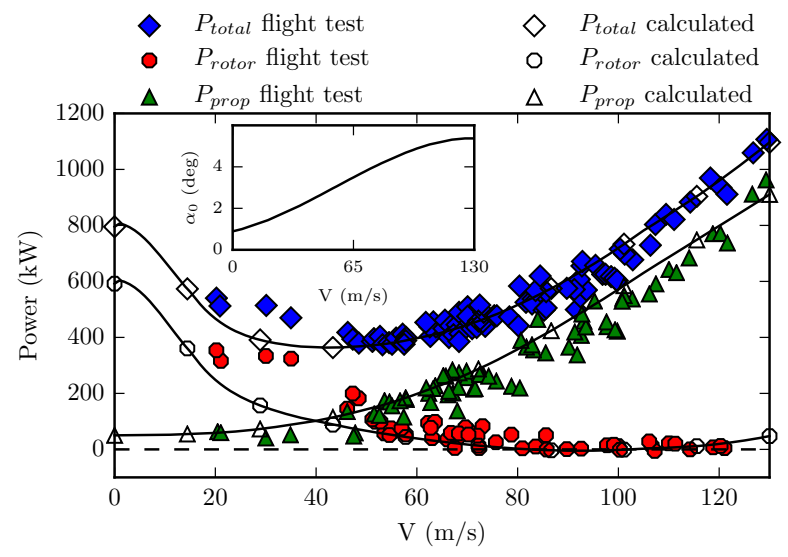

Figure 5: Performance of the rotorcraft model compared to the flight test data 12 ]

With $P_{\text {total }}$ established, an off-design operating point for the engine model was calculated with TURBOMATCH. However, the evaluation of the gaseous emissions of the engine combustor is not yet undertaken. 
This task is completed with the use of a second Cranfield University "in-house" tool called HEPHAESTUS. The code is based on the stirred reactor concept where turbulent flows are idealised following a stochastic representation in the combustor primary zone. The combustor is represented by individual stirred reactors, incorporating the processes of mixing, combustion heat release, and pollutant formation. A more thorough explanation can be found in 26]. HEPHAESTUS requires combustor geometry, as well as the air mass flow distribution along the combustor. The code has the ability to account for the impact of atmospheric conditions, fuel composition and gas temperature and pressure. HEPHAESTUS has proven itself to be an effective tool for rotorcraft environmental studies in the past [27].

\subsection{Optimisation Strategy}

As highlighted by the previous section, the environment in which the study is found is a numerical compound of integrated interdependent disciplines. The complexity of the analysis captures the synergies between each discipline but at relatively high computational cost as the optimisation process is realised at mission level, rather than at single operation point. Indeed, in order to simulate a rotorcraft mission, the mission profile is truncated into discrete segments with a user defined time step $\Delta t$. At each iteration, the atmospheric conditions are evaluated. The vehicle is then trimmed with an iterative process and the engine off-design operating point is evaluated. The engine fuel flow and its gaseous emissions for the segment are calculated and the vehicle AUM is subsequently updated. The rotorcraft position is also updated following the mission flight path. The gradual weight reduction of the vehicle along the mission is simulated. The mission can be run multiple times to accurately estimate the mission fuel burn with an acceptable error $\epsilon$. Figure 6 summarises the presented numerical procedure.

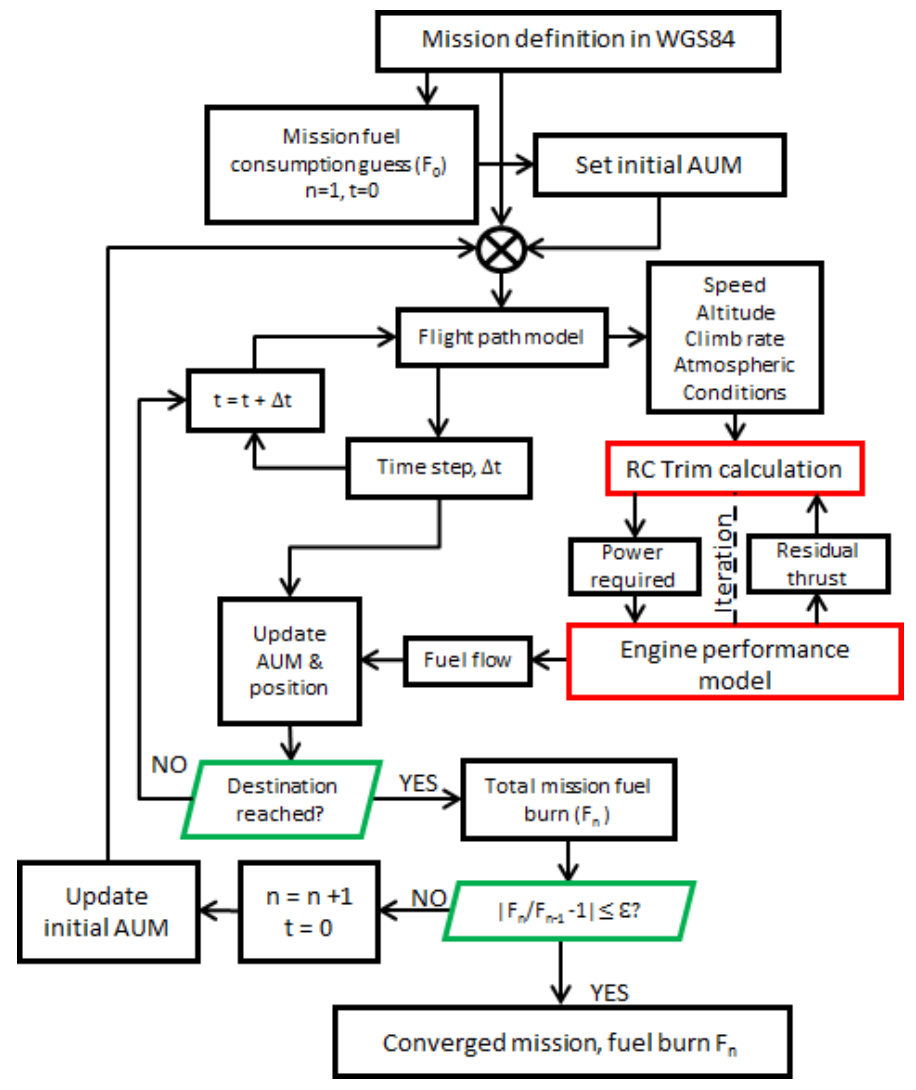

Figure 6: CRPM mission analysis scheme

Therefore, the challenge comes from the need for a certain level of simplification of the mission simulation whilst keeping a robust optimisation strategy. Following this conclusion, metamodels were generated to 
mimic the trim calculations and estimate the rotor and propeller power demand. That is to say, the RSMs maps the performance of a selected rotorcraft within its flight envelope to replace the trim calculation of CRPM. A 4D interpolation on forward speed, altitude, climb rate, and AUM is subsequently used to calculate the performance of the vehicle at any given conditions whilst the ISA deviation is selected before the generation of the RSMs. The vehicle descriptive parameters are frozen within the RSMs including the lift offset and $\alpha_{0}$ controls. The RSMs replace the trim calculation and the iterative process seen in Figure 6 therefore the engine performance model, TURBOMATCH, is maintained to evaluate engine fuel flow, allowing for preliminary assessment of conceptual powerplants. However, the residual thrust effect on the trimming process is not accounted for by the RSMs. HEPHAESTUS is also kept in the process, calculating the emitted gases. This approach allows for simultaneous engine and mission optimisation but only the latter is considered in the paper. This provides a robust and versatile platform representing a trade-off between the method followed in [6, 14, 16] and directly using the rotorcraft model.

\subsection{Optimisation Approach}

The multidisciplinary context of the problem implies the use of a robust global optimisation process. A global genetic algorithm (GA) multi-objective optimiser is employed. The used GA is part of the toolkit provided by the Distributed Evolutionary Algorithms in Python computational framework (DEAP) as described in 17. The GA method is based on a heuristic search that mimics the process of biological evolutions or in other words natural selection. It is seen as an intelligent random search to solve optimisation problems.

The evolutionary algorithm starts with a population of individuals. Each generation is created by mating and mutation from parent individuals. Parents are selected from the previous generation and the ones with better fitness have a larger probability of being selected. The mutation and mating methods and probability are set up by the user. The mating or crossover method followed executes a two points crossover on the input individuals or parents and the process of mutation follows a polynomial trend.

\section{Results \& Discussions}

\subsection{Case Study Definition}

The versatility of the developed tool allows for the assessment of conceptual coaxial rotorcraft with a pusher propeller of any given size, at any performance point or over mission role. In consequence of the passenger VIP activity growth, the present study evaluates the aforementioned architecture for this particular mission with a conceptual 3-tonne rotorcraft. As shown in Figure 1 a certain number of inputs are indispensable to set up the simulation framework. The vehicle dimensions must be specified along several attributes such as MTOW, rotor diameter, number of blades, rotor blade airfoils, etc. Table 1 details the main characteristics of the conceptual vehicle and the X2TD.

\begin{tabular}{lll}
\multicolumn{2}{l}{ Table 1: Characteristics of the conceptual rotorcraft model compared to the Sikorsky X2TD demonstrator } \\
\hline Attribute & X2TD & Concept \\
\hline \hline MTOW & $2721 \mathrm{~kg}$ & $3000 \mathrm{~kg}$ \\
Rotor diameter & $8.05 \mathrm{~m}$ & $8.40 \mathrm{~m}$ \\
Rotor configuration & 2 four-bladed coaxial rotor & 2 four-bladed coaxial rotor \\
Propeller diameter & $2.14 \mathrm{~m}$ & $2.14 \mathrm{~m}$ \\
Propeller configuration & 1 six-bladed pusher prop & 1 six-bladed pusher prop \\
Powerplant & 1 T800-LHT-801 (1,221kW) & 1 T700-GE-700 (1,350kW) \\
\hline
\end{tabular}

$M_{\text {roll }}$ of the conceptual vehicle is following the same law as the one evaluated for he X2TD with $L_{o f f s e t}^{100}$ $=15 \% . \alpha_{01}$ is set to zero while $\alpha_{02}$ is following the law determined for the X2TD. A single T700-GE700 turboshaft engine is chosen for powerplant. Although this engine is not representative of the state of the art turboshaft technology, it was chosen in consequence of the large amount of data available on its 
performance [28] and gaseous emissions [29, 30]. The comparisons between the TURBOMATCH engine performance model and the data found in [28, are exhibited in Figures 7(a) and 7(b), where GE Status 81 is an engine thermodynamic model provided by the manufacturer and the denominated NASA results are the one calculated in 28. The T700-GE-700 combustor was also modelled in HEPHAESTUS to accurately predict the $N O_{x}$ emissions of the modelled engine as illustrated in Figure 7(c). In this figure, the results obtained with HEPHAESTUS are plotted together with the experimental results obtained by Cohen [29].

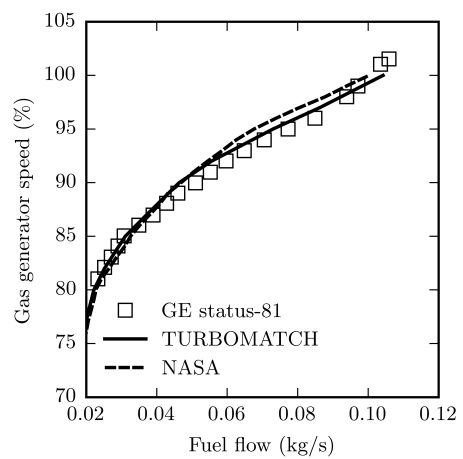

(a)

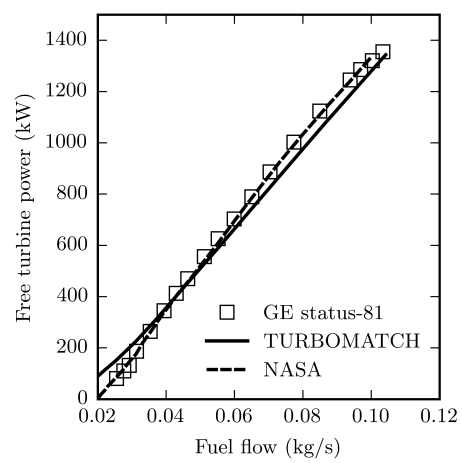

(b)

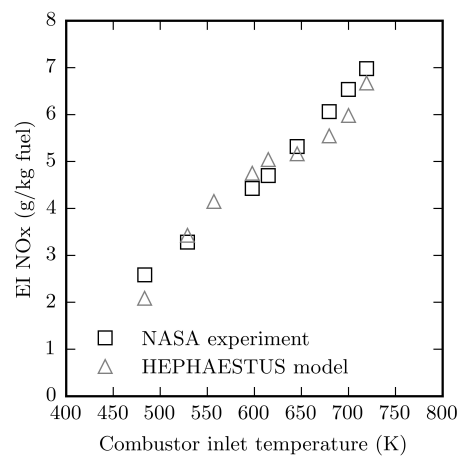

(c)

Figure 7: Validation of the T700 engine model. (a) gas generator speed vs engine fuel flow, (b) free turbine power vs engine fuel flow (c) index of $N O_{x}$ emission vs combustor inlet temperature

The conceptual vehicle is a 3-tonne single engine rotorcraft expected to fly on inter-city passenger/taxi VIP operations, over an extended range and at increased speed, compared to conventional helicopter architectures. The scenario considered has four passengers with their luggage resulting in a $620 \mathrm{~kg}$ payload. Several missions are optimised ranging from $50 \mathrm{~km}$ to $300 \mathrm{~km}$ to accurately evaluate the effect of mission distance on the overall mission optimisation. In a first instance, the focus will be put on the $300 \mathrm{~km}$ mission to then extend the discussion to the full range of mission distances. For the concern of simplicity, each mission was divided into three segments: climb, cruise and descent. Each section has two design inputs: either climb speed or altitude and forward speed. The mission parameters considered for the optimisation are given in figure 8 whilst the design space boundaries for the optimisation are shown in Table 2. The take-off and landing procedures are kept the same across the study. The mission includes a Hover Out of Ground Effect (HOGE). A $50 \mathrm{~kg}$ fuel reserve is also comprised in every mission. Constraints linked to flight procedures are not considered in the optimisation. The ISA deviation is set to zero for the study.

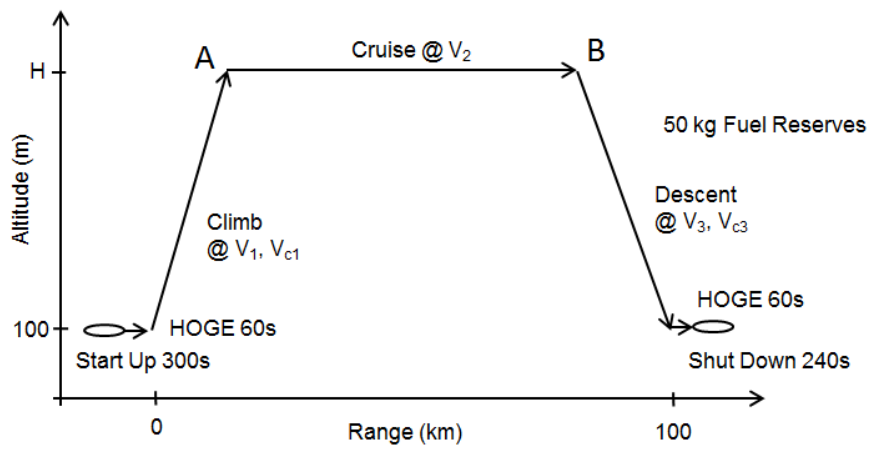

Figure 8: General mission design 
In order to correctly design the mission, the coordinates of the point B must be calculated for the mission analysis. It is referred as the distance from the landing point at which the descent phase must start, as defined in Figure 8. This is done by the optimiser which generates the mission input. As for point $\mathrm{A}$, although its position varies with the mission characteristics, its coordinates are not needed. With the complete mission defined, the rotorcraft performance can be evaluated. The mission time step used is 15 seconds, meaning that position, fuel burn and emissions are estimated every 15 seconds. The gradual reduction of the rotorcraft AUM is catered. This time step provides a balance between a smooth and accurate representation of the mission and a reasonable computational time.

Table 2: Design space bounds for mission optimisation

\begin{tabular}{ccccc}
\hline Design parameter & Units & baseline & Lower bound & Upper bound \\
\hline \hline$V_{c 1}$ & $\mathrm{~m} / \mathrm{s}$ & 5 & 1 & 7 \\
$V_{1}$ & $\mathrm{~m} / \mathrm{s}$ & 40 & 40 & 100 \\
$V_{2}$ & $\mathrm{~m} / \mathrm{s}$ & 62 & 60 & 130 \\
$H$ & $\mathrm{~m}$ & 450 & 400 & 3000 \\
$V_{c 3}$ & $\mathrm{~m} / \mathrm{s}$ & -5 & -5 & -1 \\
$V_{3}$ & $\mathrm{~m} / \mathrm{s}$ & 40 & 40 & 110 \\
\hline
\end{tabular}

\subsection{Response Surface Model Approach Results}

Once the rotorcraft performance is mapped over its flight envelope, the RSM can be created and its level of fidelity assessed. The first step of the validation is at performance point level. 10 performance points are selected through a Latin Hypercube Sampling (LHS) method within the rotorcraft flight envelope. The LHS is a near random sampling method which ensures that the point of experiments are uniformly distributed in the design space [6]. The RSM absolute error is then defined as follows:

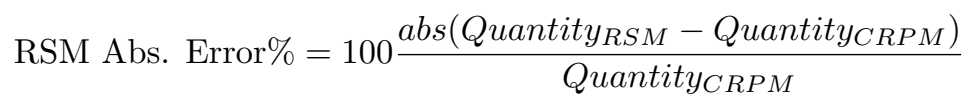

The evaluation shows an average $1.44 \%$ of absolute error in terms of power estimation, translating into a $1.03 \%$ and a $1.41 \%$ average absolute error for fuel burn and $N O_{x}$ emissions, respectively. Performance maps of the conceptual rotorcraft can then be plotted for any given condition (altitude, $A U M$, cruise speed and climb speed), assuming ISA conditions. Figure 9 provides two examples of performance maps for a given combination of $A U M$ and $H$. They show the variation of $P_{\text {rotor }}$ and $P_{\text {prop }}$ with forward and climb speed.

The second step of the verification of the RSMs is carried out at mission level. The LHS method is used within the design space bounds defined in table 2. Mission fuel burn and $N O_{x}$ emission are calculated for 10 scenarios of $100 \mathrm{~km}$ with CRPM and the RSMs. $0.27 \%$ and $0.68 \%$ absolute errors are evaluated for fuel burn and $N O_{x}$ emission respectively. The level of fidelity is considered acceptable to carry out the optimisation process. With these metamodels, a mission converges over 10 times faster than when the CRPM was employed.

\subsection{Multi-Objective Optimisation \& Results}

The $300 \mathrm{~km}$ range passenger/taxi mission is first optimised. The analysis is then extended to missions ranging from $50 \mathrm{~km}$ to $300 \mathrm{~km}$. A multi-objective environment is established to simultaneously optimise each mission in terms of duration, fuel burn and $N O_{x}$ emissions. As previously mentioned, each mission is defined by six parameters $V_{c 1}, V_{1}, V_{2}, H, V_{c 3}$, and $V_{3}$. Thanks to the optimisation, the individual effects of each parameter on the mission outputs $m_{f u e l}, m_{N O_{x}}$, and $t_{\text {mission }}$ are captured. The aforementioned are summarised in Figure 10 in the form of a simple sensitivity analysis, established based on quadratic correlations between each parameter. Although it shows only tendencies, it serves as a fair basis for making sound judgements about the influence of the parameters on the mission outputs. Indeed, it highlights the dependencies of $t_{\text {mission }}, m_{f u e l}$, and $m_{N O_{x}}$ on the mission characteristics and the presence of optima. Each parameter is discussed hereafter; 


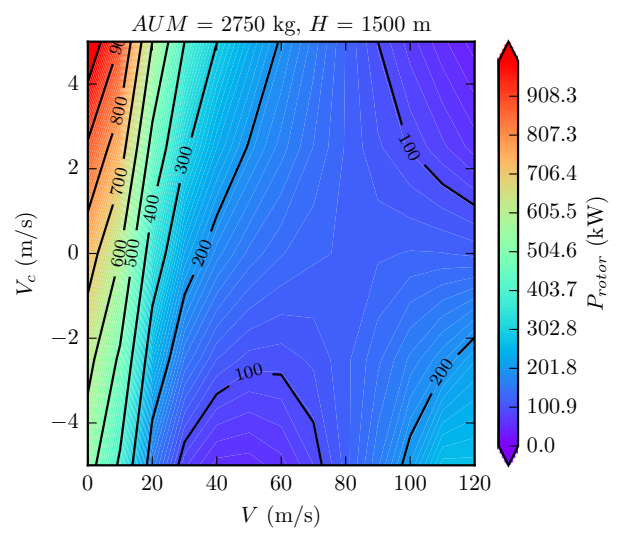

(a)

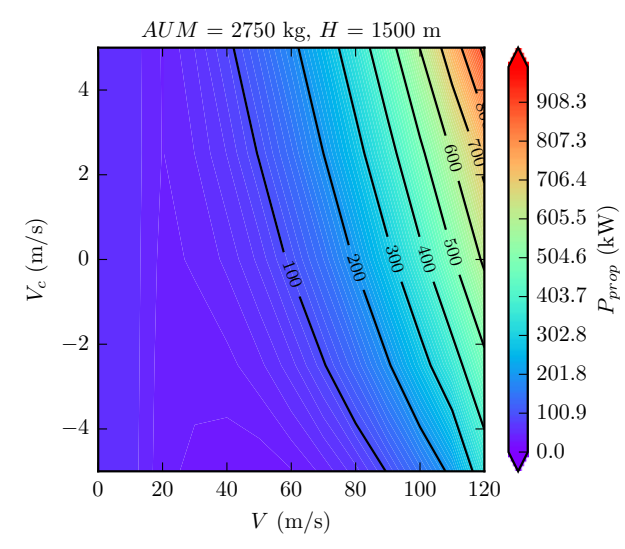

(b)

Figure 9: (a) Rotor power and (b) propeller power maps at given $A U M=2750 \mathrm{~kg}$ and $H=1500 \mathrm{~m}$ vs. forward and climb speed together

- $V_{c 1}$ : low impact on $m_{f u e l}$ and to a lesser degree $t_{m i s s i o n}$. The lowest $t_{m i s s i o n}$ and $m_{f u e l}$ are achieved with high $V_{c 1}$. $m_{N O_{x}}$ does not seem to be effected by $V_{c 1}$ in comparison with the other mission parameters.

- $V_{1}$ : similar to $V_{c 1}$.

- $V_{2}$ : the key parameter. $t_{m i s s i o n}$ decreases sharply with $V_{2}$. The variations of $V_{2}$ are impacting $t_{\text {mission }}$ roughly five times more than any other parameter. Optima appear for $m_{f u e l}$ and $m_{N O_{x}}$ at approximately $90 \mathrm{~m} / \mathrm{s}$ and $75 \mathrm{~m} / \mathrm{s}$, respectively.

- $H$ : the second key parameter, especially for $m_{f u e l}$ and to a lesser degree $m_{N O_{x}}$. The lowest $m_{f u e l}$ and $m_{N O_{x}}$ are achieved at high altitude, while the lowest $t_{m i s s i o n}$ are attained at low altitude.

- $V_{c 3}$ : similar amplitude to $V_{c 1}$. $t_{m i s s i o n}$ and $m_{f u e l}$ decrease with a drop in $V_{c 3} \cdot m_{N O_{x}}$ is not effected by $V_{c 3}$ in comparison with the other mission parameters.

- $V_{3}$ : similar impact as $V_{2}$ but to a lesser degree. Presence of an optimum for minimum $m_{\text {fuel }}$.

The key parameters in order of importance are $V_{2}$ and $H$, followed by $V_{1} V_{c 1}, V_{c 3}$, and $V_{3}$. The effect of the forward speeds $\left(V_{1}, V_{2}, V_{3}\right)$ is similar on every flight segment but its influence on the complete mission is strongly dependent upon the relative length of each leg. Figures 10(b) and 10(c) highlight the presence of optimum cruise speeds for low $m_{\text {fuel }}$ and low $m_{N O_{x}}$. They can be mathematically estimated thanks the calculation of the minimums $\frac{w_{f}}{V}$ and $\frac{w_{N} O_{x}}{V}$, where $w_{f}$ and $w_{\text {nox }}$ are the engine fuel flow speed and the engine $N O_{x}$ emissions rate. The speed of maximum range and the speed for minimum $N O_{x}$ emissions depend on the vehicle $A U M$ and flight altitude. Figure 11 shows the graphical implications of the equations.

A sensitivity analysis is also carried out on the shortest mission. As illustrated in the set of Figures 12(a) 12(c), the sensitivity study over the shortest mission $(50 \mathrm{~km})$ is by many means different from the $300 \mathrm{~km}$ mission. Each mission parameter has a comparable amplitude effect on the mission outputs. They all appear to have an optimum for which $t_{\text {mission }}, m_{f u e l}$, and $m_{N O_{x}}$ are minimum. From Figure 12, every mission parameter appears to have a similar effect on every mission outputs. A unique optimum mission can be drawn for which $V_{c 1}$ is low, $V_{1}=75 \mathrm{~m} / \mathrm{s}, V_{2}=100 \mathrm{~m} / \mathrm{s}, H=1000 \mathrm{~m}, V_{c 3}=3 \mathrm{~m} / \mathrm{s}$ and $V_{3}=90 \mathrm{~m} / \mathrm{s}$.

The Pareto fronts are effectively 3 -dimensional surfaces, however, in order to ease their visualisation, the Pareto fronts are displayed with three 2-dimensional projections. Figure 13 shows the Pareto fronts for 300 


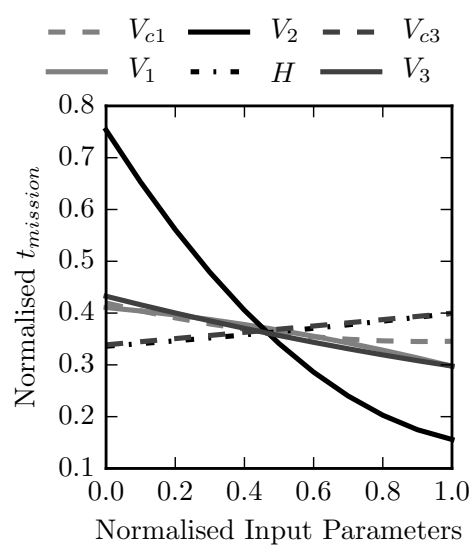

(a)

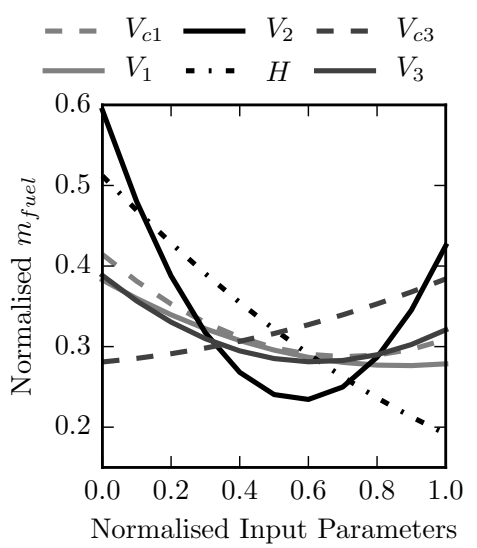

(b)

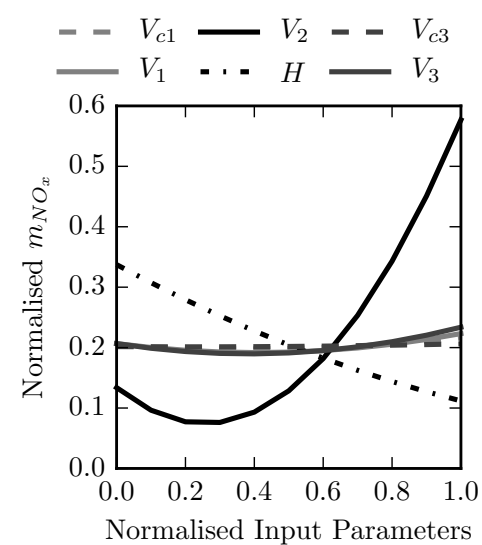

(c)

Figure 10: Sensitivity analysis of the missions characteristics on (a) $t_{\text {mission }}$, (b) $m_{f u e l}$, and (c) $m_{N O_{x}}$ on the 300 km scenario

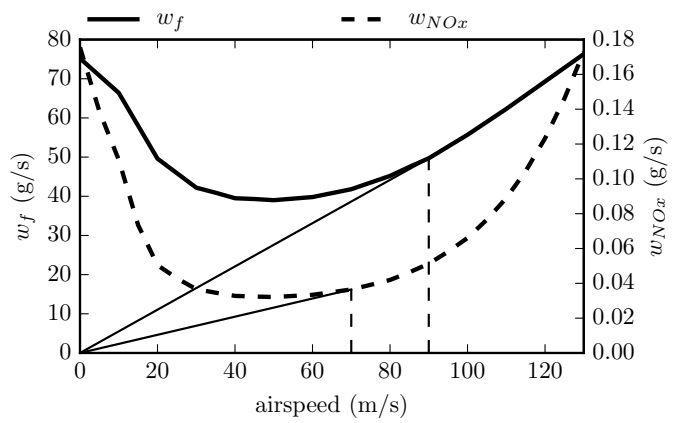

Figure 11: Engine fuel flow and $N O_{x}$ emissions versus forward speed, $V$, for $H=1500 \mathrm{~m}$ and $A U M=2750 \mathrm{~kg}$

$\mathrm{km}$ and $50 \mathrm{~km}$ mission scenarios. The level of shade of each visible individual is defined by the following equation:

$$
\omega=\left(\frac{t_{\text {mission }}}{t_{\text {mission }}^{\text {max }}}\right)^{2}+\left(\frac{m_{\text {fuel }}}{m_{\text {fuel }}^{\text {max }}}\right)^{2}+\left(\frac{m_{N O_{x}}}{m_{N O_{x}}^{\text {max }}}\right)^{2}
$$

The lower $\omega$ is, the darker the individual is. Ideally, a dark individual represents an attractive solution to the optimisation problem. Figure $13(\mathrm{a})$ highlights the conflicts between $t_{\text {mission }}, m_{f u e l}$, and $m_{N O_{x}}$. Indeed, a quick mission results in high level of $N O_{x}$ emissions which does not imply a high mission fuel burn. A minimum $m_{\text {fuel }}$ appears at $t_{\text {mission }}$ around $4000 \mathrm{~s}$. Figure $13(\mathrm{~b})$ underlines apparent linear relations between $t_{\text {mission }}, m_{f u e l}$, and $m_{N O_{x}}$ which disappear as the mission length increases. This behaviour greatly simplifies the problem for short missions. A single objective optimisation would have been sufficient for the given optimisation scenario. It confirms the highlights of sensitivity analysis discussion on the $50 \mathrm{~km}$ mission (Figure 12), where a unique optimum was drawn.

A best estimate mission scenario is selected from the Pareto fronts providing a trade-off between each output. The exercise is executed for each mission range. In each case, the picked missions are actually really close if not the $m_{f u e l}$ optimised scenarios themselves, corresponding to the points marked in Figure 13. Therefore the problem could be simplified to a single objective optimisation on $m_{f u e l}$. The interdependencies between the mission characteristics and missions outputs are shown in Figure 14 in the form of a simple 


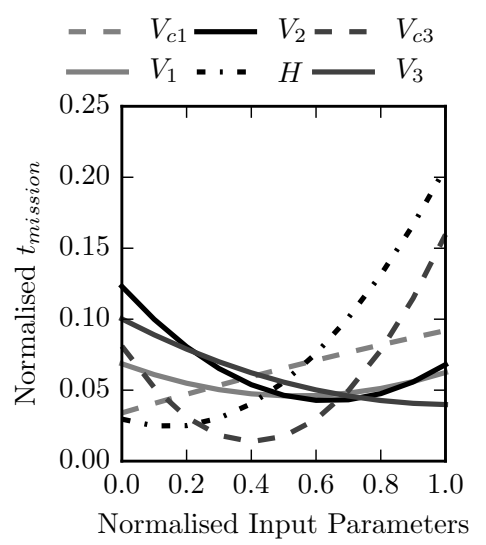

(a)

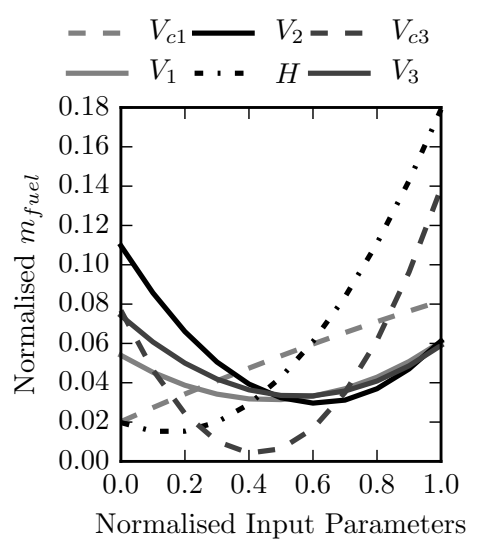

(b)

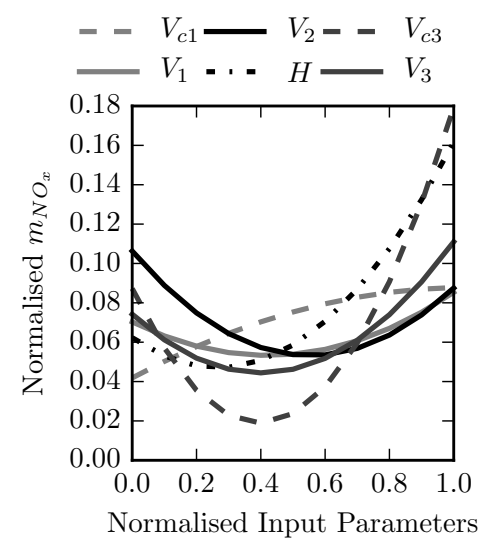

(c)

Figure 12: Sensitivity analysis of the missions' characteristics on (a) $t_{\text {mission }}$, (b) $m_{f u e l}$, and (c) $m_{N O_{x}}$ on the 50 km scenario
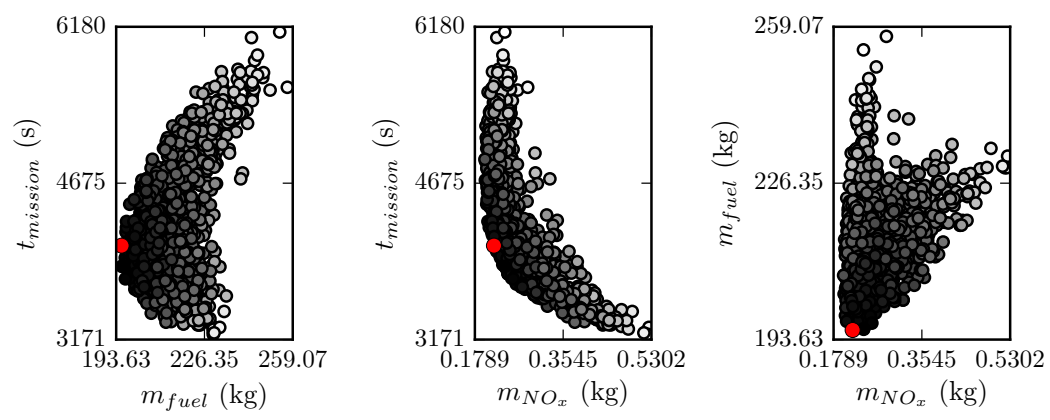

(a) $300 \mathrm{~km}$
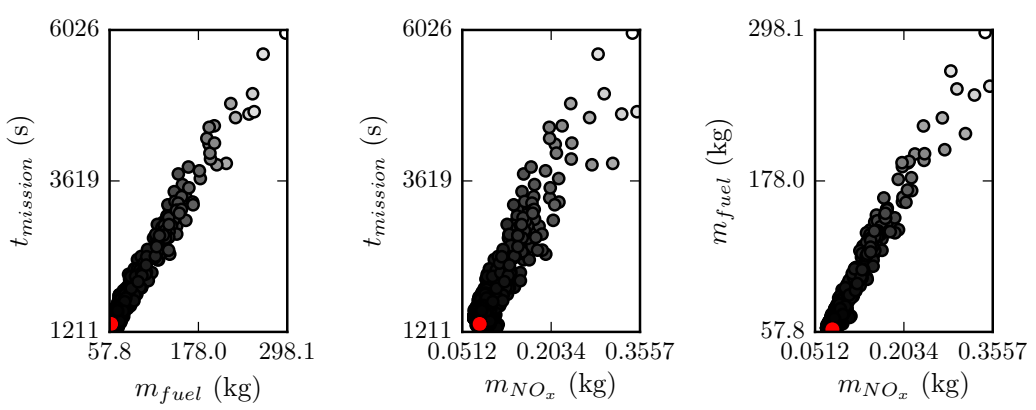

(b) $50 \mathrm{~km}$

Figure 13: 2 Dimensional representation of the Pareto fronts for two scenarios:(a) $300 \mathrm{~km}$ and (b) $50 \mathrm{~km}$

sensitivity analysis. The plot is based on linear correlations between each parameter. Although the analysis suggests a linear relation between the various parameter, this may not be the case. It only presents the trend followed by the parameters with mission range. 


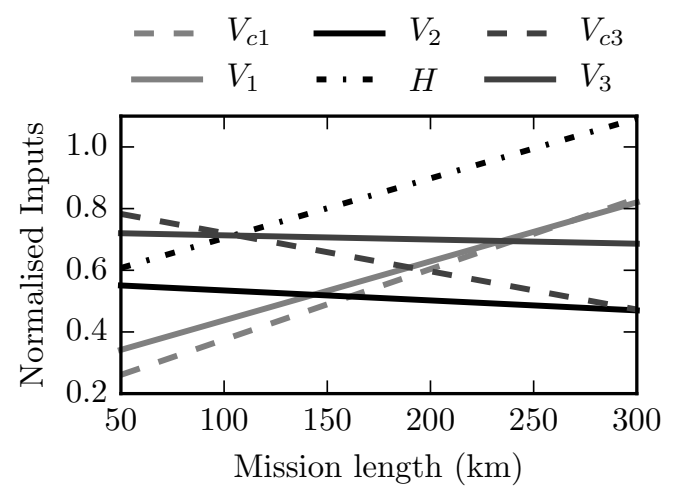

Figure 14: Sensitivity analysis for the missions' characteristics against range

Table 3 completes the sensitivity analysis. $V_{c 1}$ and $V_{1}$ increase with mission range. $H$ also increases with the mission length. It actually raises from $1000 \mathrm{~m}$ on the $50 \mathrm{~km}$ mission to hit the upper bound of the optimisation $(3000 \mathrm{~m})$, on the $100 \mathrm{~km}$ mission. Above, the cruise altitude remains at $3000 \mathrm{~m}$. An average altitude of $2913 \mathrm{~m}$ with a variance of $83 \mathrm{~m}$ is found when only the ranges above $100 \mathrm{~km}$ are considered. $V_{2}$ remains uniform across the study at about $96 \mathrm{~m} / \mathrm{s}$. As for the descent leg, $V_{c 3}$ remains relatively constant around $-2.5 \mathrm{~m} / \mathrm{s}$ with a slight decrease as the range increases. Similarly, $V_{3}$ is also relatively constant across the study with an average of $92 \mathrm{~m} / \mathrm{s}$.

Table 3: Average and variance of the mission design inputs over the study

\begin{tabular}{cccc}
\hline Design parameter & Units & Average Optimum & Variance \\
\hline \hline$V_{c 1}$ & $\mathrm{~m} / \mathrm{s}$ & 4.2 & 1.8 \\
$V_{1}$ & $\mathrm{~m} / \mathrm{s}$ & 78.5 & 13.4 \\
$V_{2}$ & $\mathrm{~m} / \mathrm{s}$ & 95.9 & 9.2 \\
$H$ & $\mathrm{~m}$ & 2580 & 691 \\
$V_{c 3}$ & $\mathrm{~m} / \mathrm{s}$ & -2.5 & 0.9 \\
$V_{3}$ & $\mathrm{~m} / \mathrm{s}$ & 92.2 & 4.8 \\
\hline
\end{tabular}

Thanks to the mission optimisation, average reductions of $23 \%, 20 \%$, and $13 \%$ are simultaneously achieved on $t_{\text {mission }}, m_{f u e l}$, and $m_{N O_{x}}$ when compared to the results of the different mission ranges with the baseline scenario presented in Table 2. The average optimum speeds and climb rates provided in Table 3 can be taken to define a much "improved" mission scenario without the need for an optimisation. The average cruise altitude, on the other hand, should be defined as a function of mission range, for missions under $100 \mathrm{~km}$. With these characteristics, 22\%, 14\%, and 8\% reduction are achieved, respectively. The cruise altitude is chosen for each mission range in agreement with the optimisation process.

\section{Conclusions \& Future Work}

A new multidisciplinary design and optimisation methodology was developed for design and analysis of conceptual coaxial rotorcraft with a pusher propeller architecture. A rotorcraft simulation framework was deployed. It is able to compute rotorcraft performance and engine performance alongside its gaseous emissions for any conceptual rotorcraft at both performance point and mission level. A comprehensive multi-objective optimisation strategy was deployed with the extensive use of metamodels. A GA optimiser was implemented and applied to the multidisciplinary optimisation of a passenger taxi VIP mission for a conceptual coaxial rotorcraft modelled after the Sikorsky X2TD vehicle. 
With regards to the present work, the multi-objective optimisation highlighted the conflicting interrelations between mission duration, fuel burn and $N O_{x}$ emissions. This is particularly true when the mission is above $100 \mathrm{~km}$. Fast missions are only achieved at the price of high $N O_{x}$ emissions. Emphasis was made on the requirement to adapt the flight procedures for the next generation of rotorcraft which will have different characteristics and specifications. Improvement in flight duration alongside reductions in emissions were achieved with regards to the baseline mission. The possibility to simplify the multi-objective optimisation to a single-objective one on the mission fuel burn was also highlighted. It provides a trade-off between a short mission duration and low $N O_{x}$ emissions. Thanks to the optimisation, a procedure for an improved overall mission was evaluated independently of the mission range. It provides a flight path adapted to the conceptual compound vehicle, resulting in mission duration reduced by $22 \%$ on average for all the cases. Therefore, such vehicles may be of interest for the future dense air traffic.

\section{Nomenclature}

\section{Acronyms \& Abbreviation}

$A U M$ All-Up-Mass (kg)

$\mathrm{CO}_{2}$ carbon dioxide

CRPM Coaxial Rotorcraft Performance Model

LHS Latin Hypercube Sampling

$\mathrm{NO}_{x} \quad$ nitrogen-oxides

$V T M$ Vorticity Transport Model

X2TD Sikorsky X2 Technology Demonstrator)

ACARE Advisory Council for Aeronautics Research in Europe

DEAP Distributed Evolutionary Algorithms in Python

GA Genetic Algorithm

HOGE Hover Out of Ground Effect

MTOW Maximum Take-Off Weight (kg)

RSM Response Surface Model

WGS 84 World Geodetic System date 1984

\section{Roman Symbols}

$C_{P} \quad$ rotor power coefficient (-)

$C_{T} \quad$ rotor thrust coefficient (-)

$P_{\text {prop }}$ rotorcraft propeller rotor power $(\mathrm{kW})$

$P_{\text {rotor }}$ rotorcraft coaxial rotor power $(\mathrm{kW})$

$P_{\text {total }}$ rotorcraft total power $(\mathrm{kW})$

$t \quad$ time (s)

$w_{f} \quad$ engine fuel flow $(\mathrm{kg} / \mathrm{s})$ 


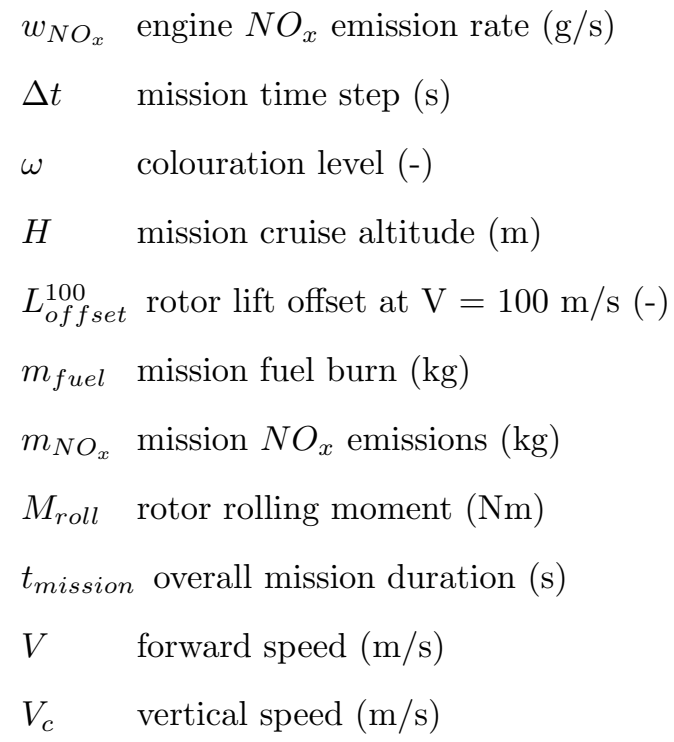

\section{Superscripts}

1 first segment of the mission: climb

2 second segment of the mission: cruise

3 third segment of the mission: descent

\section{References}

[1] Air Transport Action Group (ATAG),accessed on 19/11/15 URL http://www . atag.org/facts-and-figures.html

[2] J. A. Leggett, B. Elias, D. T. Shedd, Aviation and the European Union's Emission Trading Scheme, Tech. rep. (2012). URL https://www.fas.org/sgp/crs/row/R42392.pdf

[3] Aviation Environment Federation, accessed on 04/03/16 URL http: //www . aef .org.uk/

[4] UK parliamentary Office of Science and Technology Report April 2003, accessed on 19/11/15. URL http://www .parliament.uk/documents/post/pn195.pdf

[5] EUROCONTROL, Seven-year forecast, Tech. rep. (2016). URL http://www . eurocontrol.int/publications/eurocontrol-seven-year-forecast-february-2016

[6] R. D'Ippolito, J. Stevens, V. Pachidis, A. Berta, I. Goulos, C. Rizzi, A Multidisciplinary Simulation Framework for Optimization of Rotorcraft Operations and Environmental Impact, in: 2nd International Conference on Engineering Optimization (EngOpt 2010), Lisbon, Portugal, September, 2010, pp. 6-9.

[7] Advisory Council for Aeronautics Research in Europe, Strategic Research Agenda. Tech. rep. (2002). URL http://ec.europa.eu/research/transport/pdf/acare\{_\}strategic\{_\}research\{_\}en.pdf

[8] High Level Group on Aviation Resarch- European Commission, Flightpath 2050- Europe's VIsion for Aviation, Tech. rep. (2011).

URL http://ec.europa.eu/transport/sites/transport/files/modes/air/doc/flightpath2050.pdf

[9] J.-P. Clarke, The role of advanced air traffic management in reducing the impact of aircraft noise and enabling aviation growth, Journal of Air Transport Management 9 (3) (2003) 161-165.

[10] P. Brooker, Civil Aircraft Design Priorities: Air Quality? Climate Change? Noise?, The Aeronautical Journal 110(1110) $517-532$

[11] Sikorsky S-97 RAIDER About, accessed on 15/10/15 URL http://raider.sikorsky.com

[12] D. Walsh, S. Weiner, K. Arifian, T. Lawrence, M. Wilson, T. Millott, R. Blackwell, High Airspeed Testing of the Sikorsky X2 Technology (TM) Demonstrator, in: 67th Annual Forum of American Helicopter Society, Sikorsky Aircraft Corporation, Virginia Beach, 2011.

[13] W. Johnson, J. F. Elmore, E. B. Keen, A. T. Gallaher, G. F. Nunez, Coaxial Compound Helicopter for Compound Urban Operations, AHS Specialists' Conference on Aeromechanics Design for Vertical Lift.

[14] I. Goulos, V. Pachidis, R. DIppolito, J. Stevens, C. Smith, An Integrated Approach for the Multidisciplinary Design of Optimum Rotorcraft Operations, Journal of Engineering for Gas Turbines and Power 134 (9) (2012) 091701. 
[15] I. Goulos, P. Giannakakis, V. Pachidis, P. Pilidis, Mission Performance Simulation of Integrated HelicopterEngine Systems Using an Aeroelastic Rotor Model, Journal of Engineering for Gas Turbines and Power 135 (9) (2013) 091201.

[16] A. Fakhre, K. Tzanidakis, I. Goulos, V. Pachidis, R. D'Ippolito, Multi-Objective Optimization of Conceptual Rotorcraft Powerplants: Trade-off Between Rotorcraft Fuel Efficiency and Environmental Impact, Journal of Engineering for Gas Turbines and Power 137 (7) (2014) 071201. doi:10.1115/1.4029103

[17] F.-A. Fortin, F.-M. De Rainville, M.-A. Gardner, M. Parizeau, C. Gagné, DEAP: Evolutionary algorithms made easy, Journal of Machine Learning Research 13 (2012) 2171-2175.

[18] V. Pachidis, P. Pilidis, L. Marinai, T. Templalexis, Towards a Full Two Dimensional Gas Turbine Performance Simulator, The Aeronautical Journal 111 (1121) (2007) 433-442.

[19] J. G. Leishman, Principles of Helicopter Aerodynamics, 2nd Edition, Cambridge aerospace series, Cambridge University Press, 2006

[20] J. Yana, O. Rand, Performance Analysis of a Coaxial Rotor System in Hover: Three Points of View, Tech. rep., International Congress of the Aeronautical Sciences (2012).

[21] R. D. Harrington, Full-Scale-Tunnel Investigation of the Static-Thrust Performance of a Coaxial Helicopter Rotor, Tech. rep. (1951).

[22] H. W. Kim, R. E. Brown, A Comparison of Coaxial and Conventional Rotor Performance, Journal of the American Helicopter Society 55 (1) (2010) 12004.

[23] W. L. Macmillan, Development of a Module Type Computer Program for the Calculation of Gas Turbine Off Design Performance, Ph.d. thesis, Cranfield University, Cranfield, Bedfordshire, UK (1974).

[24] Y.-G. Li, L. Marinai, V. Pachidis, E. L. Gatto, P. Philidis, Multiple-Point Adaptive Performance Simulation Tuned to Aeroengine Test-Bed Data, Journal of Propulsion and Power 25 (3) (2009) 635-641.

[25] A. Bagai, Aerodynamic Design of the Sikorsky X2 Technology Demonstrator Main Rotor Blade, 64th Annual forum at American Helicopter Society, Montréal, Québec, Canada (2008) 16.

[26] C. Celis, B. Moss, P. Pilidis, Emissions Modelling for the Optimization of Greener Aircraft Operations, Combustion, Fuels and Emissions 2 (2009) 167-178. doi:10.1115/GT2009-59211

[27] I. Goulos, F. Ali, K. Tzanidakis, V. Pachidis, R. D'Ippolito, A Multidisciplinary Approach for the Comprehensive Assessment of Integrated Rotorcraft-Powerplant Systems at Mission Level, Journal of Engineering for Gas Turbines and Power 137 (012603-1) (2015) 11.

[28] Ballin, M. G., A high fidelity real-time simulation of a small turboshaft engine, Tech. rep., NASA Ames Research Center; Moffett Field, CA, United States (1988). doi:NASA-TM-100991

[29] U. S. Cohen, J. D. (General Electric Co., Lynn, Ma, Analytical fuel property effects, small combustors, phase 1, Tech. rep., NASA-CR-168138 (apr 1983).

[30] T. G. Hill, J. D. Monty, H. L. Morton, Analytical fuel property effects: Small combustors, phase 2, Tech. rep., NASACR-174848 (mar 1985). 
2017-10-31

\section{Mission optimisation for a conceptual coaxial rotorcraft for taxi applications}

Enconniere, Julien

Elsevier

Enconniere J, Ortiz-Carretero J, Pachidis V. (2018) Mission optimisation for a conceptual coaxial rotorcraft for taxi applications. Aerospace Science and Technology, Volume 72, January 2018, pp. 14-24

https://doi.org/10.1016/j.ast.2017.10.031

Downloaded from Cranfield Library Services E-Repository 